\title{
EDUCATIONAL CHALLENGES DURING THE PANDEMIC
}

\author{
R. Robert Gajewski \\ Warsaw University of Technology, Faculty of Civil Engineering \\ Aleja Armii Ludowej 16, 00-637 Warszawa, Poland \\ rg@il.pw.edu.pl, ORCID 0000-0002-2521-6559
}

\begin{abstract}
The article summarizes one year of pandemic education. After presenting the calendar of events, the author describes his motivation to prepare this paper, presents the review of last year's literature. He refers to several basic educational terms and describes his experiences with Small Private Online Courses (SPOC) and an educational newsletter. Further, the author discusses simple ways of preparing multimedia objects of knowledge and proposes to use the paradigm of flipped education accomplished by formative assessment as well as making materials available in the framework of the Synchronous Online Flipped Learning Approach (SOFLA). Remote evaluation of learning outcomes is difficult and problematic mainly because of the e-cheating problem. The effectiveness of SOFLA during the pandemic was investigated in the same way as in China. Results of both surveys were compared. The article is supplemented by some comments regarding the future of education based on a comparative analysis of the situation of teachers in Poland and around the world.
\end{abstract}

Keywords: pandemic education, flipped classroom, formative assessment, blended learning, learning objects.

\section{INTRODUCTION}

The article was created in three stages. Its first version was drafted in May 2020 for a conference, which was cancelled. The second version was created in September. The final version is of July 2021. The article has changed significantly over the last few months. During the pandemic, the government and ministries have reduced resolving pandemic education problems to issuing ineffective laws, regulations, and recommendations. If educators themselves do not do something constructive to save education, no one will do it for them. All lessons learned during the pandemic and described in the paper are of great importance for the future of education. 


\section{LITERATURE REVIEW}

During the past year there were many papers published on pandemic education. Teräs et al. (2020) studied post-COVID-19 education and education technology solutionism. Dhawan (2020) raised an important question of whether online learning is a panacea in the time of the COVID-19 crisis. Nartiningrum \& Nugroho (2020) investigated challenges, suggestions, and needed materials by students of English as a Foreign Language. Bailey et al. (2020) worked on finding intrinsic motivation for synchronous and asynchronous communication in the online language learning context. Lassoued et al. (2020) performed an exploratory study of the obstacles to achieving quality in distance learning during the COVID-19 pandemic. Colomo-Magaña et al. (2020) studied university students' perception of the usefulness of the flipped classroom methodology. Arora \& Srinivasan (2020) investigated the impact of the COVID-19 pandemic on the teaching-learning process: a study of higher education teachers. In China during the pandemic there was a lot of research on different online learning and teaching models. Zhang et al. (2020) studied factors affecting Chinese university students' intention to continue using virtual and remote labs, which is crucial for technical studies. Wong (2020) tried to answer an important question - when no one can go to school, does online learning meet students' basic learning needs? Jiang et al. (2021) tried to measure online learning satisfaction in higher education during the COVID-19 pandemic and prepared a regional comparison between Eastern and Western Chinese universities.

\section{SPOC AND NEWSLETTER}

The concept of Small Private Online Courses (SPOC) was first introduced by Fox (2013). Ever since then such courses have been progressively implemented in higher education as a new approach to education (Ruiz-Palmero et al., 2020). To some extent SPOC replaced Massive Open Online Courses (MOOC), which have a very high drop-out rate (Eriksson et al., 2017). The course on Technology Enhanced Learning for faculty staff members was created on March 15, 2020, as a SPOC. This is an example of a course that was created without any funding but only within the framework of broadly understood educational volunteering. In the original version, this was primarily a place where questions could be answered in the discussion forum. Later, materials were added to the course showing how to prepare Learning Objects (Polsani, 2003) in multimedia and reusable form (Neto et al., 2017). Seven different types of multimedia recordings were recognized: whiteboard (simulation of a whiteboard in class), slides (classical slides with audio track and video), mixer (use of different sources), mixer plus (use of slides and whiteboard at the same time), paper (use of scanned paper notes), talking head and audio talk.

Later, in June 2020, the faculty educational newsletter was started. Lessons learned from the course were very simple. People do prefer to obtain a letter rather than to follow the course. Newsletters in the electronic version contained links to the course which was used more frequently as a result. 


\section{EDUCATIONAL SENECA EFFECT}

In his book "The Seneca Effect" (Bardi, 2017) Ugo Bardi tried to explain why growth is slow, but collapse is rapid. This is an extension of a line written by a Roman Stoic philosopher Lucius Annaeus Seneca: "Fortune is of sluggish growth, but ruin is rapid". Thoughts from this book were expanded in a new one entitled "Before the Collapse" (Bardi, 2020) which is a kind of a guide to the other side of growth. The Seneca effect is also visible in education especially because of the pandemic COVID-19. The erosion of the educational system is caused by many factors. The first one is growing bureaucracy. The second element accelerating the collapse of the education system is negative selection for the teaching profession. Another element that enhances the journey towards the Seneca educational cliff is cyber diseases mentioned by Manfred Spitzer in his books about digital dementia (Spitzer, 2014), cyber diseases (Spitzer, 2017), and digital discomfort (Spitzer, 2020). The alpha generation is very seriously threatened by digital dementia, a disease caused by an uncontrolled use of digital media. This phenomenon can be especially dangerous for children and adolescents, whose brains are more malleable and absorb external stimuli like a sponge.

\section{FLIPPED CLASSROOM AND FORMATIVE ASSESSMENT}

Remote classes were conducted using a flipped education approach in which direct instruction moves from the group learning space to the individual learning space, and the resulting group space is transformed into a dynamic, interactive learning environment where the educator guides students as they apply concepts and engage creatively in the subject matter. One of the problems which arise in the case of remote classes is the assessment process and evaluation of learning outcomes. Classical exams and tests have limited value because of e-cheating. That is why formative assessment was used introducing a frequent, interactive assessment of a student's progress and understanding of the material so the teachers can determine how the students learn and how to teach them in the best way.

\section{SOFLA MODEL}

The Synchronous Online Flipped Learning Approach (SOFLA) model was presented for the first time by Marshal and published by Marshall \& Kostka (2020). SOFLA was developed to align flipped learning principles with online instruction. In this approach flipped learning moves to asynchronous space. In-class work completes in synchronous class sessions when students and teachers are present. The key advantage of this approach is that by meeting synchronously regularly teachers and students can clearly distinguish between two contexts of the learning process: in-class synchronous and out-of-class asynchronous. The effectiveness of SOFLA during the COVID-19 pandemic was investigated by Ma (2020) from Xi'an International University. No other results concerning the investigation of SOFLA are available now. The survey participants were 60 second-year undergraduates in a pre-service 
English teacher training program at a private university in China. An anonymous online survey was designed with the consideration of the Community of Inquiry framework (Garrison et al., 2001) and students' satisfaction questionnaire prepared by Wu et al. (2010). The survey covered five parts: social presence, teaching presence, cognitive presence, teaching evaluation, and learning effect, with 17 items in total. The survey was built on a five-point Likert scale (range from "strongly dissatisfy" to "strongly satisfy", 1-5). Table 1 presents the results of the survey. Results in grey columns are for Poland.

In January 2021 an identical survey took place at the Faculty of Civil Engineering of Warsaw University of Technology. 140 students were participating in this survey out of the total number 160. The surveys were conducted during the course described in (Gajewski et al., 2013). This course as described in (Gajewski \& Jaczewski, 2014) is taught in a flipped format. Figure 1 presents results in graphical form. Black columns and lines are for Chinese results, grey are for Polish.

Table 1. Results of surveys (grey background - results for Poland)

\begin{tabular}{lllll}
\hline \multicolumn{1}{c}{ Detailed description } & M & SD & M & SD \\
\hline Social presence & & & & \\
1 Enhanced communication between T \& Ss and Ss \& Ss & 4.30 & 0.71 & 2.93 & 1.07 \\
2 Improved ways and forms of interaction between T and Ss & 4.09 & 0.70 & 3.05 & 0.99 \\
3 Maintained sustainable interest and attention & 3.46 & 0.56 & 2.89 & 1.12 \\
Teaching presence & & & & \\
4 Clear objectives for learning tasks & 4.01 & 0.53 & 3.63 & 1.08 \\
5 Just-in-time teaching or peer instruction & 4.28 & 0.58 & 3.42 & 0.97 \\
6 Just-in-time supervision and reminder by the teacher & 4.15 & 0.74 & 3.39 & 1.04 \\
Cognitive presence & & & & \\
7 Promoted autonomous learning and personalized learning & 4.26 & 0.72 & 3.26 & 1.09 \\
8 Upgraded learning motivation & 3.96 & 0.67 & 2.68 & 1.26 \\
9 Rich types of online learning resources & 4.35 & 0.69 & 3.43 & 1.05 \\
10 Various forms of in-class learning activities & 4.23 & 0.73 & 3.00 & 0.96 \\
11 Improved knowledge digestion and absorption & 4.16 & 0.84 & 2.86 & 1.04 \\
Teaching evaluation & & & & \\
12 Beneficial to monitor, supervise, and feedback of learning & 4.24 & 0.63 & 3.12 & 1.04 \\
13 Helpful to examine learning effect in time & 4.03 & 0.66 & 3.32 & 1.00 \\
Learning effect & & & & \\
14 Improved communication and expression sills & 4.15 & 0.75 & 2.74 & 1.03 \\
15 Promoted the ability to think critically and solve problems & 3.87 & 0.79 & 3.20 & 1.04 \\
16 Enhanced the ability to use information technology & 4.17 & 0.68 & 3.69 & 0.98 \\
17 Improved learning effect in general & 4.20 & 0.62 & 3.10 & 1.06 \\
\hline
\end{tabular}

S ource: Own work based on (Ma, 2020).

It is easily visible that average values $(\mathrm{M})$ are higher for China and standard deviation values (SD) are smaller for China. This means that Polish students are less satisfied with the SOFLA model but on the other hand, their opinions are more varied. It is 
a challenge to convince those who are not satisfied because education will change. The biggest differences in average values (M) are for the questions concerning enhanced communication (social presence) and improved communication and expression skill (learning effect). The smallest differences in averages are for questions concerning clear objectives for learning tasks (teaching presence) and enhanced ability to use information technology (learning effect).

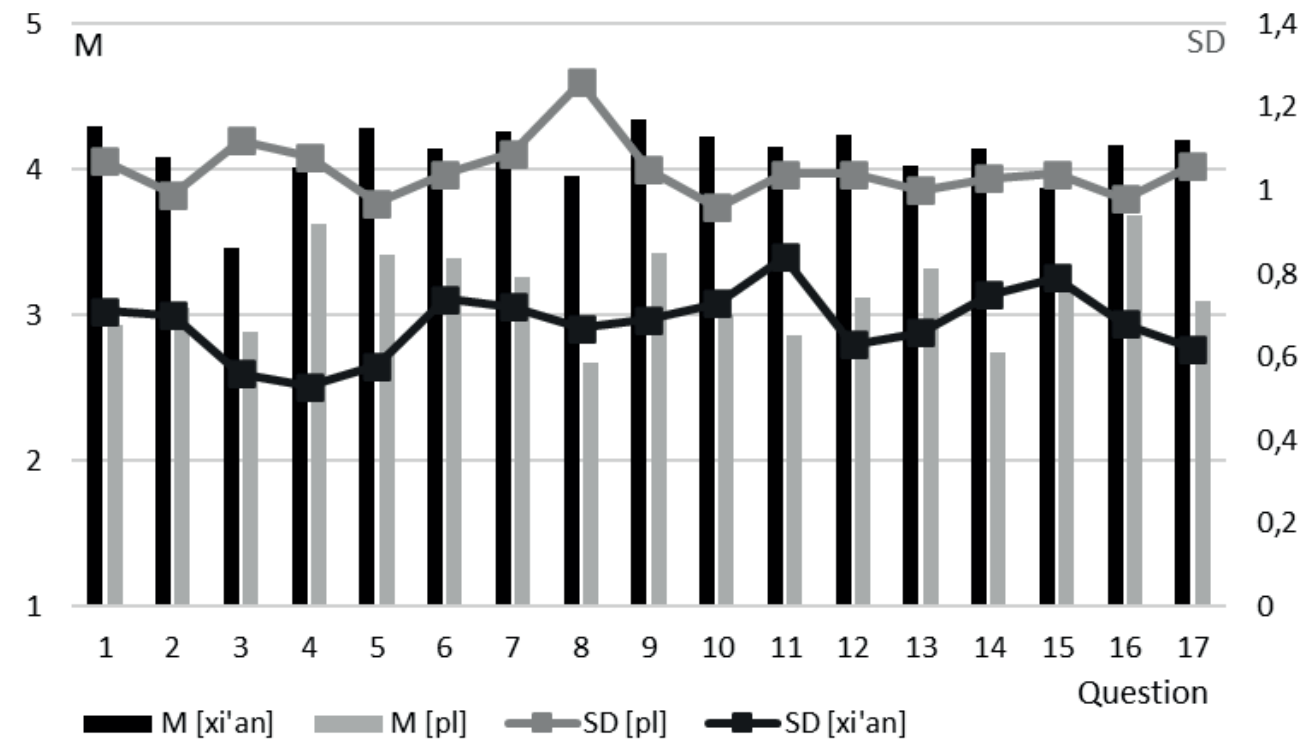

F i g u r e 1. Comparison of results of surveys

Source: Own work.

\section{HYBRID OR BLENDED?}

For three semesters in principle, all of Poland's higher education institutions worked in a fully remote mode. In the last semester, elementary and secondary schools returned to classroom-based learning. Only when the epidemic threat increased were some of the classes moved to virtual space. This method is referred to in Poland as hybrid education, although a more correct term would probably be hybrid teaching. Hybrid teaching can therefore be defined as a mixture of synchronous teaching in the classroom and in virtual space. A completely different approach is blended learning. It is a combination of synchronous classroom teaching and asynchronous e-learning (see Figure 2).

During a webinar at the Warsaw University of Technology in May 2021, which was devoted to education during the pandemic, after explaining the concepts of hybrid and blended learning, a survey was conducted among the participants. Fifty-one out of 110 registered participants of the meeting (academic teachers and students) completed the questionnaire, which is less than half. This does not necessarily mean a low interest in the survey. During webinars participants often only log in and do not actively participate in the event. 


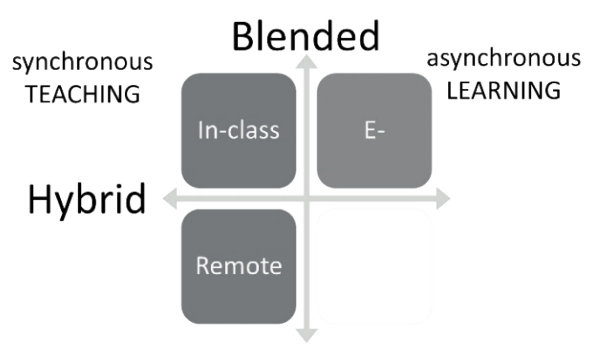

\section{F ig u r e 2. Hybrid is not blended}

S ource: Own work.

The first two questions were about the respondent's opinion on hybrid and blended education - how do you rate the idea of hybrid (blended) classes. There were four possible answers: very negative, negative, positive, very positive - according to the four-point Likert scale. The results of the surveys are shown in Figure 3. Hybrid teaching was evaluated negatively and very negatively by exactly $33.3 \%$ of the respondents. In the case of blended learning, there was no very negative evaluation only $9.8 \%$ of respondents evaluated this option negatively.
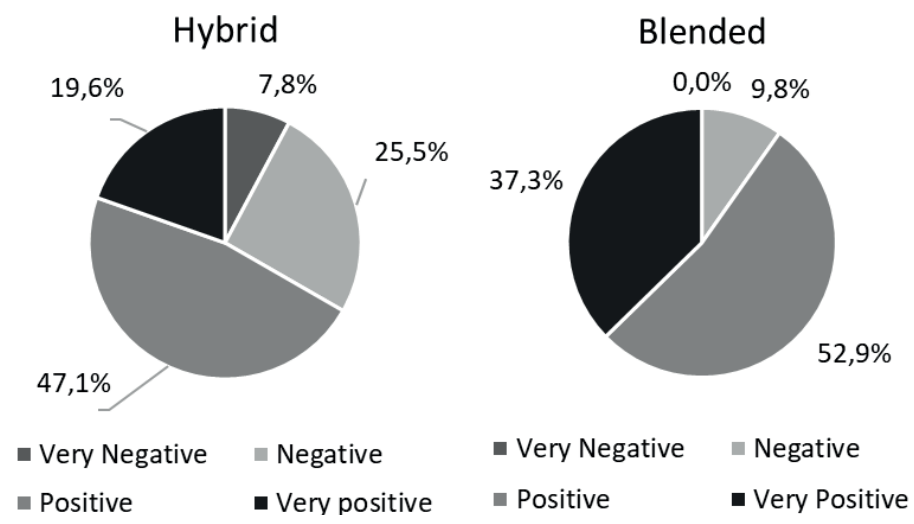

Fig u re 3. Attitude to hybrid and blended education

Source: Own work.

The third question concerned the choice of the form of teaching if there was only an exclusionary alternative - hybrid or blended. The vast majority or $68.6 \%$ chose the blended form. This is shown in Figure 4. However, this does not translate into a decision made by the university authorities. The plan is to fully return to full-time classes and in the case of an increased pandemic threat, teaching in remote or hybrid mode. The reasons for the fact that although blended learning is rated higher, it is not the choice of the majority of teachers, and above all the university authorities should be sought in administrative and financial issues. Mastering remote teaching required a lot of work on the part of teachers and the financial resources of schools. Blended learning requires the preparation of e-learning courses which means additional expenses. Because of the approaching fourth wave, this step, although expensive, should be taken. 


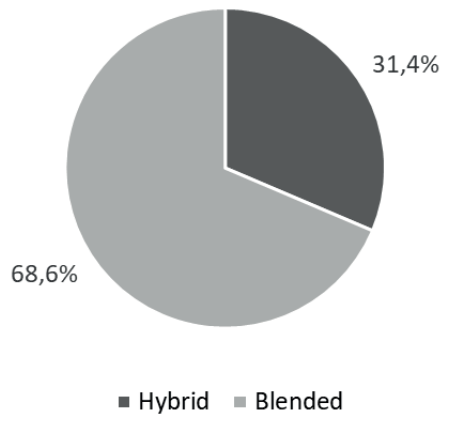

Fig u r e 4. Hybrid or blended?

Source: Own work.

\section{CONCLUSION}

For the past thirty years education and higher education have never been a real priority for all Polish governments. Today, because of the pandemic situation, it is even worse. The OECD annual report shows in a chapter about indicator D3 - how much are teachers and schools heads paid. Salaries of Polish teachers are in terms of purchasing power of money several times lower than in Germany, Denmark, and Spain. The only chance to change this situation is a common reaction of all stakeholders of the educational process - pupils, their parents, students and, teachers.

A year and a half of the pandemic education has allowed you to learn a lot. The primary lessons learned are as follows. We must consider the generation gap between baby boomers and generation $\mathrm{Z}$ in the education process. The primary sources of information are completely different for these generations. And it is the baby boomers who need to adapt to the preferences of generation $\mathrm{Z}$ and not the other way around. We cannot focus only on teaching. We must focus our efforts on helping students learn. The SOFLA model seems very promising, but it should only be a temporary solution. The target educational model should be blended learning. Especially because, according to the Seneca effect, a full return to the pre-pandemic situation will not be possible.

The main educational challenge today is the need to focus more on pupils and students and their learning in isolation. This requires a change in the way teachers approach their tasks and responsibilities. A similar change should also occur at the level of policymakers who are most willing to hold teachers accountable simply for the number of hours they teach.

The greatest threat today seems to be the practical impossibility of reliably controlling the effects of the educational process. E-cheating is the scourge of pandemic education. Problems which were solved for traditional education (Gajewski, 2016) are insoluble in remote education. It is not possible to universally organize exams based on the open book exam model.

All lessons learned during the pandemic and described in the paper can be of great importance for all teachers working on different levels of education. Education after the pandemic will not be the same as before mainly due to different restrictions. 


\section{ACKNOWLEDGEMENTS}

The author would like to express his gratitude to all students and teachers who participated in the survey. The final form of the paper was positively influenced by numerous conversations with companions in the misery of pandemic education.

\section{REFERENCES}

A ror a, A.K. \& S ri niv a s a n, R. (2020). Impact of Pandemic COVID-19 on the Teaching Learning Process: A Study of Higher Education Teachers. Prabandhan: Indian Journal of Management, 13(4), 43-56. https://doi.org/10.17010/pijom/2020/v13i4/151825.

Bailey, D., Almusharraf, N., \& Hatcher, R. (2020). Finding satisfaction: Intrinsic motivation for synchronous and asynchronous communication in the online language learning context. Education and Information Technologies. https://doi.org/10.1007/s106 39-020-10369-z.

B ardi, U. (2017). The Seneca Effect: Why Growth is Slow but Collapse is Rapid. Springer International Publishing. https://doi.org/10.1007/978-3-319-57207-9.

B a rd i, U. (2020). Before the Collapse: A Guide to the Other Side of Growth. Springer International Publishing. https://doi.org/10.1007/978-3-030-29038-2.

Colomo-Maga ña, E., Soto-Varela, R., Ruiz-Palmero, J., \& Gómez-García, M. (2020). University Students' Perception of the Usefulness of the Flipped Classroom Methodology. Education Sciences, 10(10), 275. https://doi.org/10.3390/educsci10100275.

D h a w a n, S. (2020). Online Learning: A Panacea in the Time of COVID-19 Crisis. Journal of Educational Technology Systems. https://doi.org/10.1177/0047239520934018.

Er iks s o n, T., A d a wi, T., \& S tö hr, C. (2017). “Time is the bottleneck": A qualitative study exploring why learners drop out of MOOCs. Journal of Computing in Higher Education, 29(1), 133-146. https://doi.org/10.1007/s12528-016-9127-8.

Fox, A. (2013). From MOOCs to SPOCs. Communications of the ACM, 56(12), 38-40. https:// doi.org/10.1145/2535918.

Gajewski, R.R. (2016). IT in Educational Management: Can it Support Solution of eCheating Problem? In T. Brinda, N. Mavengere, I. Haukijärvi, C. Lewin, \& D. Passey (Eds.), Stakeholders and Information Technology in Education (pp. 104113). Springer International Publishing. https://doi.org/10.1007/978-3-319-54687-2_10.

Gajewski, R.R. \& Jaczewski, M. (2014). Flipped Computer Science Classes. Annals of Computer Science and Information Systems, 2, 795-802.

Gajewski, R.R., Własak, L., \& Jaczewski, M. (2013). IS (ICT) and CS in Civil Engineering curricula: Case study. 2013 Federated Conference on Computer Science and Information Systems, 717-720.

Garri s o n, D.R., A nd er s o n, T., \& A r ch er, W. (2001). Critical thinking, cognitive presence, and computer conferencing in distance education. American Journal of Distance Education, 15(1), 7-23. https://doi.org/10.1080/08923640109527071.

J i a n g, H., I s l a m, A.Y.M.A., G u, X., \& S p e c to r, J.M. (2021). Online learning satisfaction in higher education during the COVID-19 pandemic: A regional comparison between East- 
ern and Western Chinese universities. Education and Information Technologies. https:// doi.org/10.1007/s10639-021-10519-x.

La s s o u ed, Z., A lhend aw i, M., \& B a sh it i alsh a e r, R. (2020). An Exploratory Study of the Obstacles for Achieving Quality in Distance Learning during the COVID-19 Pandemic. Education Sciences, 10(9), 232. https://doi.org/10.3390/educsci10090232.

$\mathrm{M}$ a, G. (2020). The Effectiveness of Synchronous Online Flipped Learning in College EFL Reading Course During the COVID-19 Epidemic. Research Square. https:/doi.org/10.21203/ rs.3.rs-84 578/v1.

Marshall, H.W. \& Ko st ka, I. (2020). Fostering Teaching Presence through the Synchronous Online Flipped Learning Approach. TESL-EJ, 24(2). https://eric.ed.gov/?id=EJ126 8565.

Nart in ing r u m, N. \& N u groho, A. (2020). Online Learning amidst Global Pandemic: EFL Students' Challenges, Suggestions, and Needed Materials. ENGLISH FRANCA Academic Journal of English Language and Education, 4, 115-140. https://doi.org/10.29240/ ef.v4i2.1494.

Net o, C. de S.S., Li m a, T. de S., D a m a s ce n o, A.L. de B., \& B u s s o n, A.J.G. (2017). Creating Multimedia Learning Objects. Proceedings of the $23^{\text {rd }}$ Brazillian Symposium on Multimedia and the Web, 19-21. https://doi.org/10.1145/3126858.3131626.

Pols a n i, P.R. (2003). Use and Abuse of Reusable Learning Objects. Journal of Digital Information, 3(4), Article 4. https://journals.tdl.org/jodi/index.php/jodi/article/view/jodi-105.

Ruiz - Palmero, J., Fernández-Lacorte, J.-M., Sá nchez-Rivas, E., \& Colomo Maga ña, E. (2020). The implementation of Small Private Online Courses (SPOC) as a new approach to education. International Journal of Educational Technology in Higher Education, 17(1), 27. https://doi.org/10.1186/s41239-020-00206-1.

S p it z e r, M. (2014). Digitale Demenz: Wie wir uns und unsere Kinder um den Verstand bringen ( $9^{\text {th }}$ ed.). Droemer TB.

S p it z e r, M. (2017). Cyberkrank!: Wie das digitalisierte Leben unsere Gesundheit ruiniert ( $3^{\text {rd }}$ ed.). Droemer TB.

S pit z e r, M. (2020). Digitales Unbehagen: Risiken, Nebenwirkungen und Gefahren der Digitalisierung. mvg Verlag.

Ter ä s, M., S u or a n ta, J., Terä s, H., \& C u r cher, M. (2020). Post-COVID-19 Education and Education Technology 'Solutionism': A Seller's Market. Postdigital Science and Education, 2(3), 863-878. https://doi.org/10.1007/s42438-020-00164-X.

Wo n g, R. (2020). When no one can go to school: Does online learning meet students' basic learning needs? Interactive Learning Environments, 0(0), 1-17. https://doi.org/10.1080/10 494820.2020 .1789672 .

W u, J.H., Te n n y s o n, R.D., \& H s i a, T.L. (2010). A study of student satisfaction in a blended e-learning system environment. Computers and Education, 55(1), 155-164. https://doi. org/10.1016/ j.compedu.2009.12.012.

Zh ang, M.-H., S u, C.-Y., Li, Y., \& Li, Y.-Y. (2020). Factors affecting Chinese university students' intention to continue using virtual and remote labs. Australasian Journal of Educational Technology, 36(2), 169-185. https://doi.org/10.14742/ajet.5939. 